\title{
Assessment of Neurobehavioral and Anti-Aging Effect of the Test Formulation in D-Galactose-Induced aging Dysfunction in Sprague Dawley Rats
}

\author{
Mahendra Kumar Trivedii ${ }^{1}$, Alice Branton ${ }^{1}$, Dahryn Trivedi ${ }^{1}$, Sambhu Charan Mondal ${ }^{2}$ and Snehasis Jana ${ }^{2 *}$ \\ ${ }^{1}$ Trivedi Global, Inc., USA \\ ${ }^{2}$ Trivedi Science Research Laboratory Pvt. Ltd., India \\ *Corresponding author: Snehasis Jana, Trivedi Science Research Laboratory Pvt. Ltd., Thane-West, Maharashtra, India
}

\begin{abstract}
The study aim was to evaluate the neurobehavioral effect of Consciousness Energy Healing Treated test formulation using behavioral test in male Sprague Dawley rats. The test formulation was divided into two parts, one was denoted as control, while the other was treated with Biofield Energy by Mr. Mahendra Kumar Trivedi (the Trivedi Effect ${ }^{\circledR}$-Consciousness Energy Healing) and defined as the Biofield Energy Treated sample. Besides, three group of animals were also received Biofield Energy Treatment by Mr. Trivedi. In Y-maze test, number of entries was significantly increased in the animals per se received Biofield Energy Treatment (-15 days) group (G6) by 176\%, 47.53\%, and $66.67 \%$ in the start arm, explored arm, and novel arm, respectively as compared to the untreated test formulation group (G4). Further, Biofield Treated animals per se + Biofield Treated test formulation (-15 days) group (G8), showed $100 \%$ and $32.74 \%$ increased the number of entries in start arm and novel arm, respectively compared to the G4 group. Moreover, percent of alternation behaviour was increased by $7.26 \%$ in the G8 as compared to the G4 group. In force swim test (FST) showed the number of climbing was significantly increased by $13.58 \%, 24.69 \%, 32.1 \%$, and $40.74 \%$ in the G5, G6, G7, and G8, respectively compared to G4 group. Swimming time was significantly increased by $9.34 \%$ and $10.31 \%$ in the G6 and G9, respectively compared to G4 group. Further, immobility time was significantly decreased by $27.91 \%, 55.81 \%, 61.63 \%$, and $11.63 \%$ in the G5, G6, G7, and G9, respectively compared to the G4 group. The results of Morris water maze (MWM) test data showed that the escape latency was significantly decreased by $12.06 \%$ (session 2), $13.04 \%$ (session 3), $14.88 \%$ (session 3), and $17.52 \%$ (session 3 ) in the G5, G7, G8, and G9 groups, respectively compared to the G4 group. The resting time was significantly ( $p \leq 0.05)$ decreased by $16.26 \%$ (session 3) and 15.45\% (session 3) in the G7 and G9, respectively compared to G4 group. Besides, total distance travelled was significantly reduced by $27.23 \%$ and $23 \%$ (in session 2) in the G5 and G9 groups, respectively compared to the G4 group. The results showed significant reduction of disease progression and disease-related symptoms in the preventive Treatment group per se and/or Biofield Energy Treated Test formulation groups (viz. G6, G7, G8, and G9) comparatively with the disease control group. Therefore, data suggest that Biofield Energy Treatment per se and Biofield Energy Treated test formulation have significant cognition and memory enhencing activity and could be utilized in various aging and neurobehavioral related disorders such as stroke, dementia, multiple sclerosis, acute confusional states (delirium), focal lesion syndromes, frontal lobe syndromes, etc.
\end{abstract}

Keywords: Biofield energy healing; The trivedi effect ${ }^{\circledR}$; Neurobehavioral; Force swim test; Spatial memory; Antiaging; Morris water maze; Y-maze test; Antiaging

Abbreviations: FST: Forced Swim Test; NIH/NCCAM: National Institute of Health/National Centre for Complementary and Alternative Medicine; SD: Sprague Dawley; Na-CMC: Sodium Carboxymethyl Cellulose; MWM: Morris Water Maze

\section{Introduction}

The behavioral test batteries are used to assess the learning and memory. Learning is a process of gathering lots of information about the outside world, and memory is the process of processing,

storing and reproducing this information in a suitable environment, where it is required. Experts reported that by 2050 up to 15 million Americans and more than 135 million people worldwide will suffer from different types of neurodegenerative disorders which affect 
memory function like Alzheimer's disease [1]. Different behavioral test is used currently among them Y-maze, force swim, and Morris water maze tests. Y-maze experiment is used to find the capability of rodents in the recognition and memory ability and it provides a fruitful information that reflects the animal's ability to recognize and remember the new environment [2]. Stress is the causation of most prevalent psychiatric challenging disorders such as depression and anxiety [3]. The rodent forced swim test (FST) is mainly used as a preclinical model for depression $[4,5]$. There was a direct correlation between integration of aging and cognitive behaviour. There is a numerous evidence suggesting that adults have more trouble learning new information, exhibit less efficient reasoning skills, are slower to respond on all types of cognitive tasks, and are more susceptible to disruption from interfering information than younger adults [6].

According to Hasher and Zacks [7], have reported that older adults are less effective at inhibiting irrelevant information than young adults. Based on the literature an importance of essential vitamins and minerals on stress-related disorders authors newly designed a proprietary test formulation consisting of zinc chloride, iron (II) sulfate, copper chloride, magnesium gluconate hydrate, cholecalciferol (vitamin $\mathrm{D}_{3}$ ), vitamin $\mathrm{B}_{6}$ (pyridoxine $\mathrm{HCl}$ ), and vitamin $B_{12}$ (cyanocobalamin), which would be able to combat with stress-related disorders. Biofield Therapy has been established to be an alternative medicine approach effectively used on various properties of living organisms in a cost-effective manner [8]. Every living system bearing kind of unique quality vital force, an élan vital, which gives them special quality so called 'life' [9]. This ambiguous vital force defined as the 'Bioenergetics Field'. Many alternative therapies, medicines and practices such as Tai Chi, natural products, chiropractic/osteopathic manipulation, deep breathing, yoga, meditation, Qi Gong, special diets, massage, homeopathy, guided imagery, progressive relaxation, acupuncture, acupressure, relaxation techniques, hypnotherapy, movement therapy, healing touch, rolfing structural integration, pilates, mindfulness, traditional Chinese herbs and medicines, Ayurvedic medicine, naturopathy, aromatherapy, essential oils, cranial sacral, and Reiki therapy are extensively used as a complementary and alternative medicine (CAM) system. Although, a human has the ability to acquire the vital force energy from the universe and can transmit it into a useful way that is called Biofield Energy and the process is called as "Biofield Energy Treatment/Healing". Biofield (putative energy fields) or electromagnetic based energy therapies used to promote health and healing that had been exclusively reported by the National Institute of Health/National Center for Complementary and Alternative Medicine (NIH/NCCAM) [10]. The Trivedi Effect ${ }^{\circledR}$ has been published in numerous peer-reviewed science journals with significant outcomes in many scientific fields such as cancer research [11,12], microbiology [13-16], biotechnology [17,18], pharmaceutical science [19-22], agricultural science [23-26], materials science [27-30], nutraceuticals [31,32], skin health, human health and wellness. Depending on the importance of herbs and various essential vitamins and minerals on cognitive disorders and aging, the outstanding effects of Biofield Energy Healing in multiple-fields authors hypothesized that the Biofield Energy Treated test formulation may able to combat with cognitive and aging-related disorders rats model. Therefore, authors performed this study to evaluate the effects of Biofield Energy Treated and untreated test formulation through the measurement of different behaviour parameters in male Sprague Dawley rats.

\section{Materials and Methods}

\section{Chemicals and reagents}

Cholecalciferol (vitamin $\mathrm{D}_{3}$ ), copper chloride, iron (II) sulfate, and sodium carboxymethyl cellulose (Na-CMC) were procured from Sigma-Aldrich, USA. Zinc chloride, vitamin $\mathrm{B}_{6}$ (pyridoxine hydrochloride), cyanocobalamin (vitamin $\mathrm{B}_{12}$ ), resveratrol, and magnesium (II) gluconate were purchased from TCI, Japan. D (+) Galactose obtained from Amresco, LLC. All the other chemicals used in this experiment were analytical grade procured from India.

\section{Experimental animals}

Randomly breed male Sprague Dawley (SD) rats with body weight ranges between 240.48 to $428.27 \mathrm{gm}$ were used in this experiment. The animals were purchased from M/s. National Institute of Biologicals, India. Animals were randomly divided into nine groups based on their body weights consist of ten animals of each group. They were kept individually in sterilized polypropylene cages with stainless steel top grill having provision for holding pellet feed and drinking water bottle fitted with stainless steel sipper tube. The animals were maintained as per standard protocol throughout the experiment.

\section{Consciousness energy healing strategies}

The test formulation was divided into two parts. One part of each ingredient was considered as control, where no Biofield Energy Treatment was provided. Another part of each ingredient was received Biofield Energy Treatment by Mr. Mahendra Kumar Trivedi (known as the Trivedi Effect ${ }^{\circledR}$ ) under laboratory conditions for $\sim 3$ minutes through the Healer's unique Energy Transmission process to the test formulation. The blessing/treatment was given to the test items/animals remotely without touching in the laboratory of Dabur Research Foundation, near New Delhi, India. Besides, three group of animals were also received Biofield Energy Treatment under laboratory conditions for $\sim 3$ minutes. Similarly, the control samples were subjected to "sham" healer under the same laboratory conditions for $\sim 3$ minutes. The "sham" healer did not have any knowledge about the Biofield Energy Treatment. After that, the Biofield Energy Treated samples were kept in the similar sealed condition and used as per the study plan. The Biofield Energy 
Treated animals were also be taken back to experimental room for further proceedings.

\section{Experimental procedure}

Five days after acclimatization, animals were randomized and grouped based on body weight. Dosing for group G7 and G8 was also initiated on day -15 till end of the experiment. However, G1 to G6 and G9 animals were dosed from day 1 till the end of experiment. All the animals except G1 received D-Galactose, daily (500mg/ kg; i.p.) from day 1 to the end of the experiment. Body weight and clinical signs were taken daily throughout the experimental period. Feed consumption was measured once in a week. At the end of the experimental period, i.e., during $9^{\text {th }}$ week, all the animals were individually subjected to assessment of behavioral parameters such as Y-maze, Morris water maze (MWM) test and Forced swim test (FST). All behavioral parameters were recorded using suitable Software (Panlab, Smart 3.0) for all the animals and analyzed.

\section{Behavioral testing}

Y-maze test: Impairment of spatial memory was evaluated using a Y-maze test paradigm following chronic D-galactose administration. The Y-maze consisted of three equal-dimension arms with an angle of $120^{\circ} \mathrm{C}$. The arm closest to the experimenter was defined as the start arm in which rat was placed at the start of each trial. During trial 1 ( 5 minutes), the entrance to the novel arm was closed, limiting the animal to exploration of the start arm and the open arm. After an interval, animal was allowed to explore all three arms by having the entrance to the novel arm open. Exploratory behaviour was assessed for 5 minutes. After the last dose of D-galactose and test item to the experimental animals, the Y-maze analysis was performed on the next day to all experimental rats. Each rat was placed at the centre of the apparatus and allowed to move freely through the maze for three 8 minutes sessions. The series of arm entries was observed and the following parameters such as time spent in each arm and number of entries made into each arm were calculated. Spontaneous alternation was defined as the successive entry of the rat into the three arms in overlapping triplet sets.

Percentage alternation behaviour was calculated using Equation (1):

$=($ Successive triplet sets $/$ Total number of arm entries -2$) \mathrm{X}$ $100----------(1)$

(Successive triplet set: Entries into three different arms consecutively)

Forced swimming test (FST): The forced swim test was performed with slight modification as described [33,34]. In brief, all the animals except G1 were individually subjected to swim in a glass cylinder $(40 \mathrm{~cm}$ high, $18 \mathrm{~cm}$ in diameter) filled with water $\left(25^{\circ} \mathrm{C}\right)$ up to height of $34 \mathrm{~cm}$ for 10 minutes. In this cylinder, rats cannot touch the bottom or escape. For the first exposure, rats were placed in the water for 15 minutes of forced swimming (training session). Twenty-four hours later, rats were placed in the cylinder again for a 5-minute period (test session). In the test session rats were scored by an observer blind to the effect of test substance exposure of the animal for immobility time (floating with only small movements necessary to keep their head above water), swimming time (pedalling or making circular movements), and struggling time (climbing walls or diving attempts to escape). Water in the tank was changed after each session.

Morris water maze test: The test was performed as per with slight modification [35]. Escape platform was sub-merged $1.0 \mathrm{~cm}$ below the surface of the pool water, which was maintained at $23 \pm 2{ }^{\circ} \mathrm{C}$, and mixed with milk powder to obscure the platform. The location of the platform remained in the center of south west quadrant throughout the training period. Before the first session, each animal was put on the platform for 15 seconds, and then was given a 60 seconds free swim and then guided to the platform, where it remained for another 20 seconds. Latencies to escape from the water maze (finding the sub-merged escape platform), total distance travelled, and resting time of each animal were collected and the average value of each trial for a session was calculated.

\section{Statistical analysis}

The data were expressed as mean \pm standard error of mean (SEM) and subjected to statistical analysis using Sigma Plot (Version 11.0) using one-way ANOVA. Student's $t$-test was performed for comparison of the individual treatment group with control. The $p \leq 0.05$ was considered as statistically significant $(n=10)$.

\section{Results and Discussion}

\section{Behavioral testing}

Y-maze test: The Y-maze test for cognitive function in laboratory animals is extensively used as a tool during the development of pharmaceutical formulations to the treatment of neurodegenerative diseases [36]. This behavioral test is used for the evaluation of cognitive functions like memory and learning ability of short-term work and is based on the natural instinct of rodents to explore unknown environments [37]. The effect of the test formulation on cognitive function using Y-Maze test in male Sprague Dawley rats is shown in Figure 1. Increased frequency of number of entries in the arms was considered as improve locomotor activity and increase percentage alternation was considered as an improved spatial memory function. In this technique, parameter like number of entries was significantly increased in the animals per se received Biofield Energy Treatment (-15 days) group (G6) by 176\%, $47.53 \%$, and $66.67 \%$ in the start arm, explored arm, and novel arm, respectively as compared to the untreated test formulation group (G4). Moreover, number of entries was significantly increased by $38.02 \%$ in the Biofield Energy Treated test formulation (-15 days) 
group (G7) on explored arm compared to the G4 group. Further, in the Biofield Energy Treated animals per se + Biofield Energy Treated test formulation ( -15 days) group (G8), showed $100 \%$ and $32.74 \%$ increased the number of entries in start arm and novel arm, respectively compared to the G4 group. Further, number of entries was significantly elevated by $76 \%, 38.02 \%$, and $22.12 \%$ in start arm, explored arm, and novel arm, respectively as compared to the G4 group. Other parameter like time spent was increased by $17.58 \%$ in the Biofield Energy Treated test formulation group (G5) on start arm compared to G4 Group. Moreover, G6 group an increased time spent by $43.32 \%$ and $13.1 \%$ on explored arm and novel arm, respectively compared to the G4 group. Time spent was increased by $14.64 \%$ in the G7 group on start arm only compared to G4 group. Further, time spent was increased by $37.95 \%$ in the G9 group on explored arm as compared to the G4 group. The percent of alternation behaviour was increased by $7.26 \%$ in the Biofield Energy Treated animals per se + Biofield Energy Treated test formulation (-15 days) group (G8) as compared to the G4 group (Figure 1). Besides, in case of spontaneous alternation, where rats made alternations when they sequentially visited the three arms, without repeating any one arm [38]. The results indicated more alternation task because they spent more time to elucidate which was the last arm visited. Measurement of spontaneous alternation using a Y-maze is a test also utilized for the evaluation of habituation and spatial working memory [39]. Overall, Biofield Energy Treatment improved cognition function by significantly increasing number of entries, time spent and \% alternation compared to the untreated test formulation group.

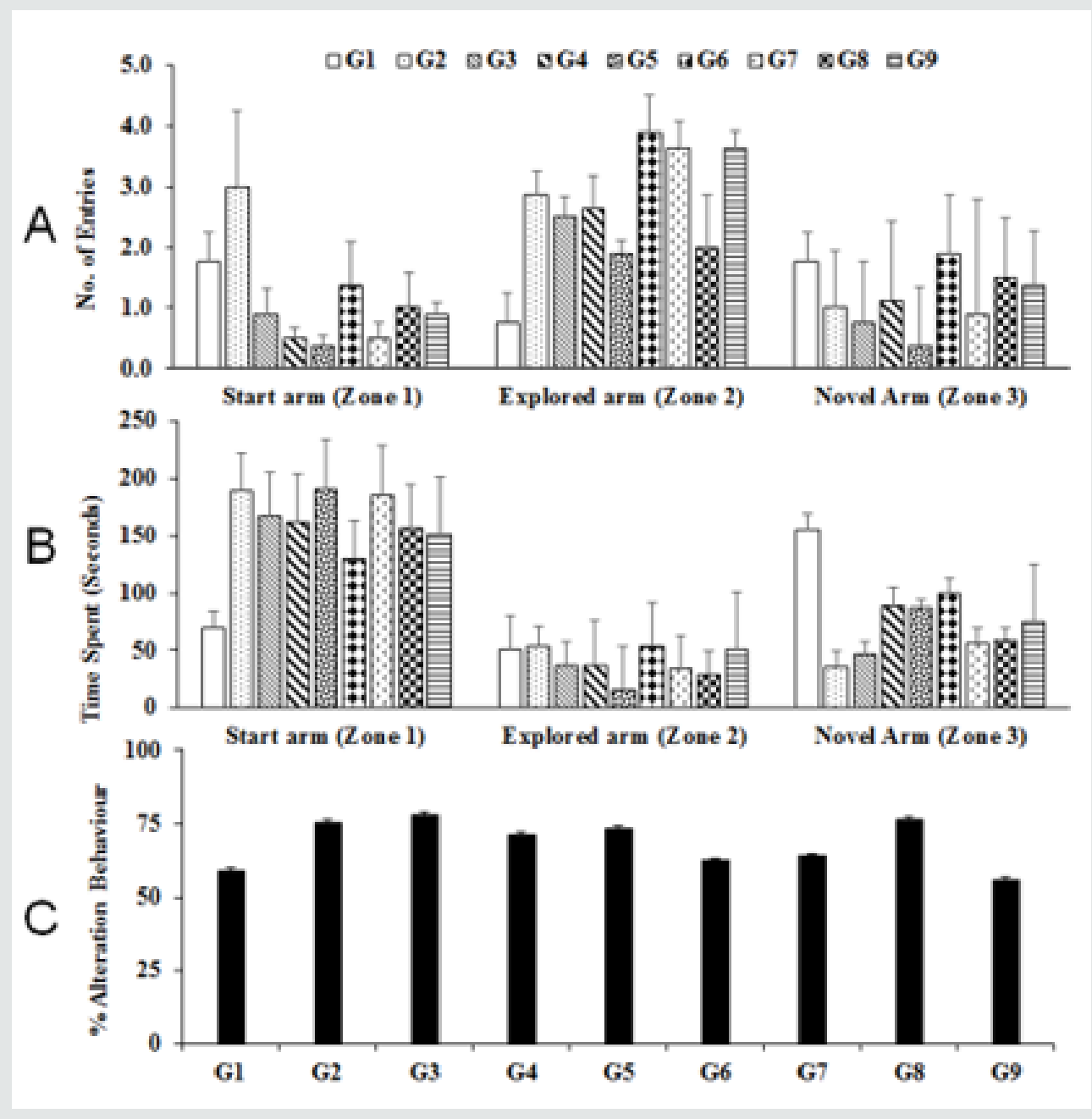

Figure 1: The cognition impairment and antiaging activities of the test formulation on male Sprague Dawley rats using Y-maze test. G1: Normal control; G2: Aging control (induced by D (+) Galactose, 500mg/kg, i.p.); G3: Resveratrol (500mg/kg, i.p.); G4: Untreated test formulation; G5: Biofield Energy Treated test formulation; G6: Animals per se received Biofield Energy Treatment (-15 days); G7: Biofield Energy Treated test formulation (-15 days); G8: Biofield Energy Treated animals per se + Biofield Energy Treated test formulation (-15 days) and G9: Biofield Energy Treatment per se to animals plus untreated test formulation. All values are presented as mean \pm S.E.M $(n=10)$. 


\section{Forced swimming test (FST)}

The results of FST after administration of the test formulation are shown in Figure 2. In this experiment, the number of climbing was significantly increased by $13.58 \%, 24.69 \%, 32.1 \%, 40.74 \%$, and $3.70 \%$ in the G5, G6, G7, G8, and G9, respectively compared to the untreated test formulation control (G4) group. Additionally, the swimming time was significantly increased by $4.67 \%, 9.34 \%$, and $10.31 \%$ in the G5, G6, and G7, respectively compared to the G4 group. Besides, the immobility time was significantly decreased by $27.91 \%, 55.81 \%, 61.63 \%, 5.81 \%$, and $11.63 \%$ in the G5, G6, G7, G8, and G9, respectively compared to the G4 group (Figure 2). The FST is another behavioral test battery normally used for rodent [40]. It is also called as Porsolt swim test developed for rats. It is used for the screening of antidepressant efficacy of new chemical entity and preventing depressive-like states $[33,41]$. It is also considered as an important tool in both academic research and drug discovery in industrial settings, where reliability and high throughput screening of novel compounds are essential [42]. Overall, the improvement of these parameters in the Biofield Energy Treated groups might be due to The Trivedi Effect ${ }^{\circledR}$-Consciousness Energy Healing Treatment.

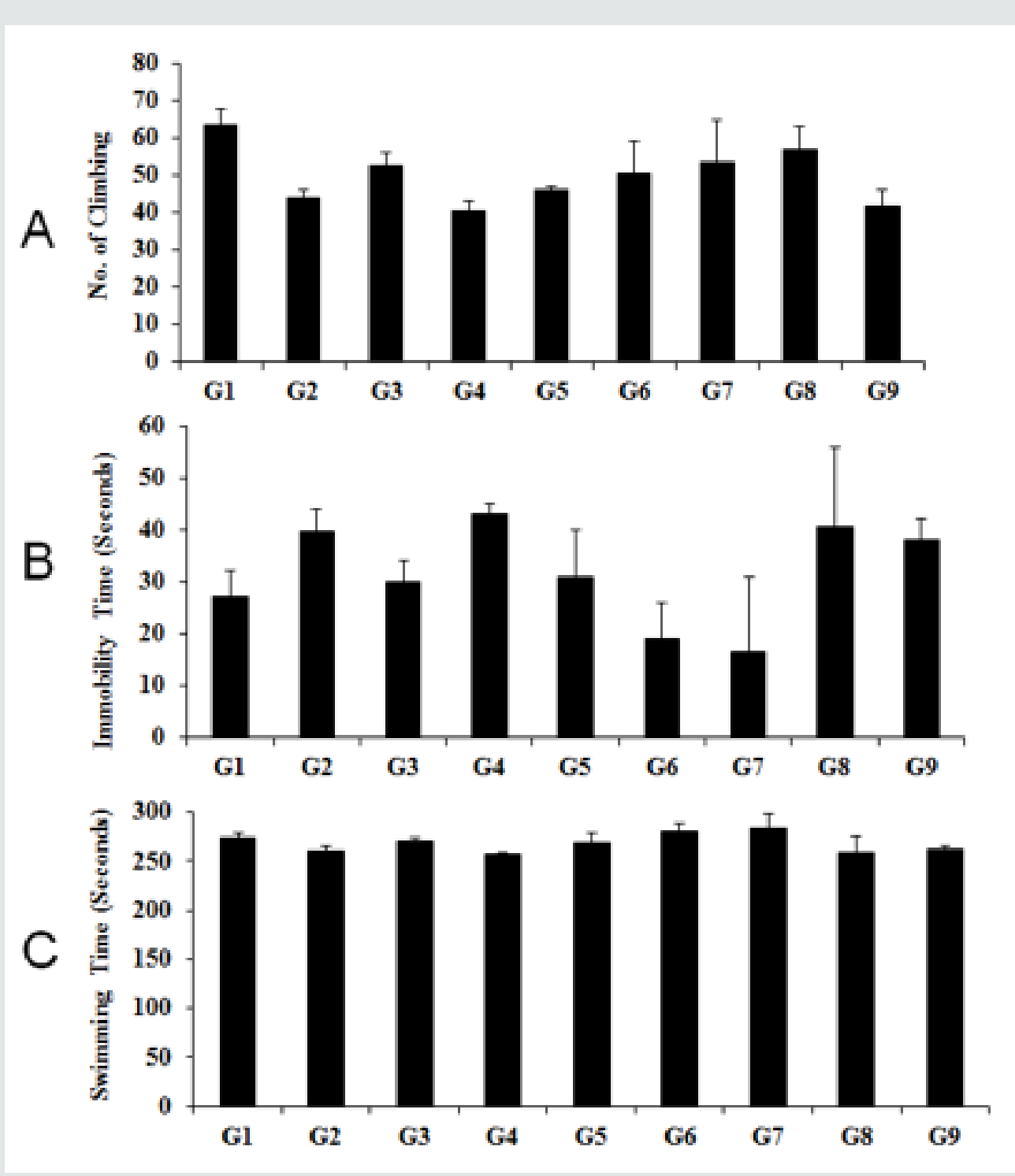

Figure 2: The behavioural and antidepressant activities of the test formulation on male Sprague Dawley rats using Force Swim Test. G1: Normal control; G2: Aging control (induced by D (+) Galactose, 500mg/kg, i.p.); G3- Resveratrol (500mg/kg, i.p.); G4-Untreated test formulation; G5-Biofield Energy Treated test formulation; G6: Animals per se received Biofield Energy Treatment (-15 days); G7: Biofield Energy Treated test formulation (-15 days); G8: Biofield Energy Treated animals per se + Biofield Energy Treated test formulation (-15 days) and G9: Biofield Energy Treatment per se to animals plus untreated test formulation. All values are presented as mean \pm S.E.M $(n=10)$. 
Morris water maze test: Many water mazes have been developed so far, but the 'the water maze' was developed by Richard Morris to assess spatial or place learning and defined as Morris water maze (MWM) [43]. For the assessment of spatial learning and memory Morris water maze test is widely used as a behavioral test $[44,45]$. The MWM is an important and dominant method has become more widely used than its predecessors such as radial-arm maze, passive avoidance, T-mazes and their variations, etc. [46]. The impact of the test formulation on activeness and spatial memory using Morris water maze test is shown in Figure 3. The escape latency was significantly reduced by $12.06 \%$ in session 2 , in the G5 group compared to the G4 group. Moreover, escape latency was decrease by $6.33 \%$ and $13.04 \%$ in session 1 and 3 , respectively in the G7 group compared to the G4 group. G8 group showed $14.88 \%$ reduction of escape latency in session 3 and G9 group showed $17.52 \%$ in session 3 compared to the G4 group. Thus, reduction of escape latency indicated that the rats learned the location of the platform during the experimental days. The parameters traveled distance and resting time were recorded additionally to avoid interpretation of confounding changes of behavior [47]. Resting time was reduced by $2.31 \%$ and $15.45 \%$ in session 2 and 3 , respectively in the Biofield Energy Treatment per se to animals plus untreated test formulation (Group 9) compared to the untreated test formulation group (G4). Further, the resting time was reduced by $16.26 \%$ in the Biofield Energy Treated test formulation (-15 days) group (G7) on session 3 compared to the G4 group.

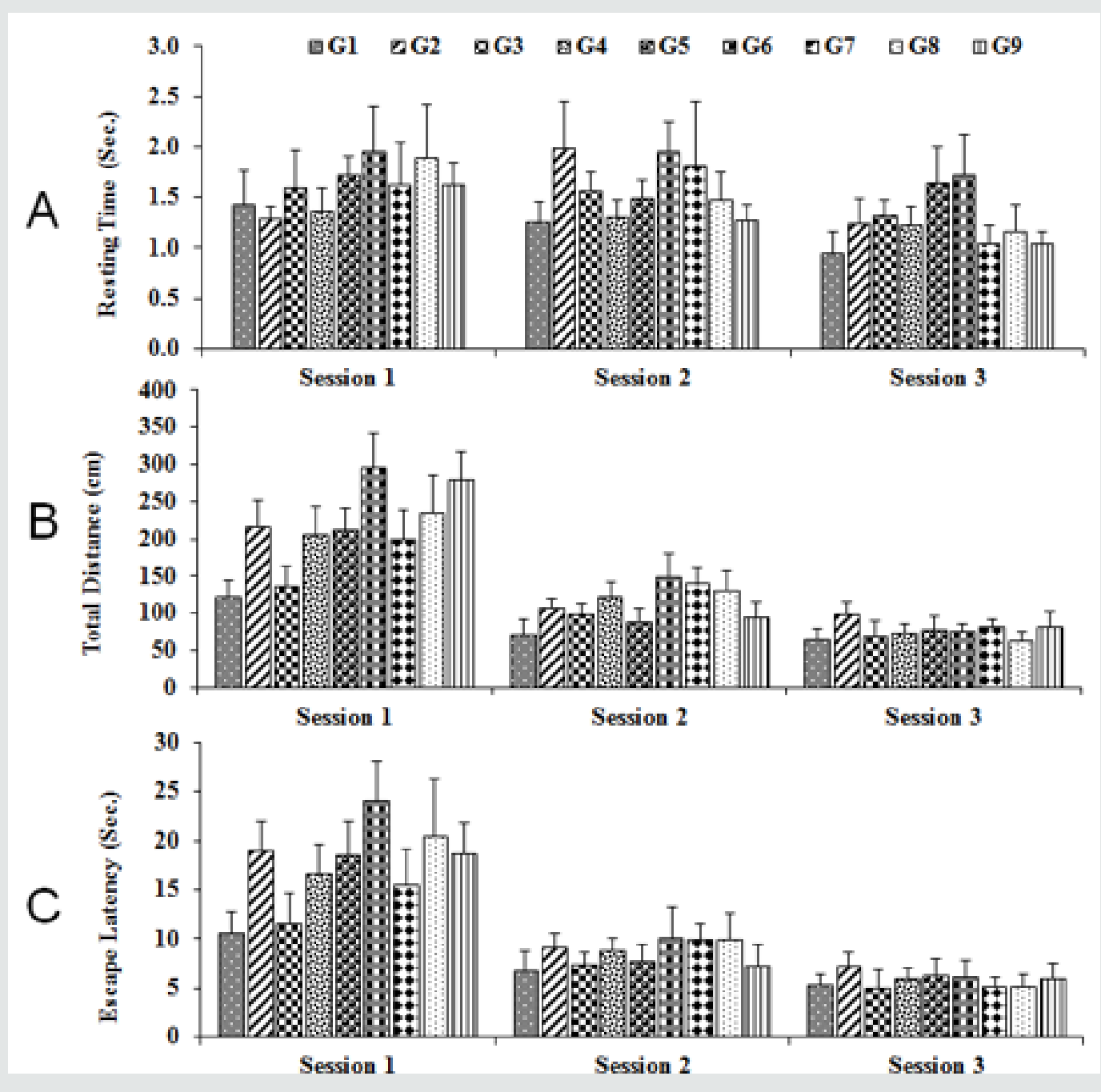

Figure 3: Representative results for the Morris Water Maze (MWM) test after treatment with the test formulation on male Sprague Dawley rats. G1: Normal control; G2: Aging control (induced by D (+) Galactose, 500mg/kg, i.p.); G3- Resveratrol (500mg/kg, i.p.); G4-Untreated test formulation; G5: Biofield Energy Treated test formulation; G6: Animals per se received Biofield Energy Treatment (-15 days); G7: Biofield Energy Treated test formulation (-15 days); G8: Biofield Energy Treated animals per se + Biofield Energy Treated test formulation (-15 days) and G9: Biofield Energy Treatment per se to animals plus untreated test formulation. All values are presented as mean \pm S.E.M $(n=10)$. 
Besides, total distance was significantly reduced by $27.23 \%$ and 23\% in session 2 in the Biofield Energy Treated test formulation group (G5) and G9, respectively compared to the G4 group. Moreover, in session 3, total distance travel was reduced by $13.76 \%$ in the Biofield Energy Treated animals per se + Biofield Energy Treated test formulation ( -15 days) group (G8) compared to the G4 group. In this research plan, four groups were considered as preventive maintenance groups. These groups were G6 (Biofield Energy Treatment per se to animals at -15 days), G7 (Biofield Energy Treated test formulation from day -15), G8 (Biofield Energy Treatment per se to animals along with Biofield Treated test formulation from day -15), and G9 (Biofield Treatment per se at -15 days to animals with untreated test formulation). The results showed the significant slowdown of the disease progression, disease related all other symptoms/complications and also reduced the chances of disease susceptibility in these groups. Specifically, group G6 (preventive Biofield Energy Treatment group per se at -15 days) showed the best results as a prophylactic/preventive treatment group compared to the other groups. Based on the overall data, it suggests that the Biofield Energy Healing Therapy was found to be most effective and benefited in order to prevent and protect from the occurrence of any type of diseases in rat model. It indicated that this therapy can act as a preventive maintenance therapy to prevent the occurrence of the disease, slow down the disease progression and disease related complications of the existing aliments that will ultimately improve the overall health and quality of life in human.

\section{Conclusion}

The result of Y-maze data suggested that number of entries was significantly elevated by $176 \%$ (in start arm), $47.53 \%$ (in explored arm), and $66.67 \%$ (novel arm) in the animals per se received Biofield Energy Treatment (-15 days) group (G6) compared to the untreated test formulation group (G4). The number of entries was also increased by $100 \%$ (in start arm) in the Biofield Treated animals per se + Biofield Treated test formulation (-15 days) group (G8) compared to the G4 group. Additionally, percent of alternation behaviour was increased by $7.26 \%$ in the G8 as compared to the G4 group. The results of force swim test showed that climbing frequency was increased by $24.69 \%, 32.1 \%$, and $40.74 \%$ in the G6, G7, and G8, respectively compared to G4 group. Parameter like immobility time was significantly decreased by $27.91 \%, 55.81 \%$, and $61.63 \%$ in the G5, G6, and G7, respectively compared to the G4 group. Besides, the results of the Morris water maze (MWM) data showed that escape latency was significantly decreased by $12.06 \%$ (session 2), 13.04\% (session 3), 14.88\% (session 3), and $17.52 \%$ (session 3) in the G5, G7, G8, G9 groups, respectively compared to the G4 group. Biofield Energy Healing Treatment (the Trivedi Effect $^{\circledR}$ ) per se showed best results with respect to different efficacy and biomarker parameters in the preventive maintenance group, G6 as compared to the other preventive maintenance groups
(G7, G8, and G9) in rat model study. It also helped to slow down the disease progression and disease related complications of the overall animal's health. These data suggested that Biofield Energy Treatment per se and/or Biofield Energy Treated Test formulation in combination would be the best treatment strategies in order to prevent and protect from the occurrence of any type of diseases.

Therefore, the Biofield Energy Treatment might act as a preventive maintenance therapy in order to maintain good health, or full restoration of health or improve the overall health and quality of life in human. This therapy might also reduce the severity of any type of acute/chronic disease (auto-immune related and inflammatory disorders) progression rate and can be used in both before and after the manifestation of any disease symptoms in healthy, unhealthy, and ill peoples. Therefore, it is assumed that the Biofield Energy Treated test formulation could be more useful in various aging and neurobehavioral-related disorders such as stroke, occlusion, hemorrhagic, transient ischemic attack (TIA), arterialvenial malformation (AVM), phenylketonia ( $\mathrm{PKU}$ ), encephalitis, amnesiac syndrome, psuedopsychiatric syndromes, visual agnosia, prosopagnosia, ideomotor apraxia, constructional apraxia, etc. Besides, it can also be utilized in organ transplants (kidney, liver, and heart transplants), various autoimmune disorders Fatigue Syndrome and Vasculitis, as well as inflammatory disorders such as such as Lupus, Addison Disease, Celiac Disease (gluten-sensitive enteropathy), Dermatomyositis, Graves' Disease, Hashimoto Thyroiditis, Rheumatoid Arthritis, Multiple Sclerosis, Myasthenia Gravis, Pernicious Anemia, Sjogren Syndrome, Scleroderma, Aplastic Anemia, Reactive Arthritis, Fibromyalgia, Disease, Psoriasis, Chronic Asthma, Systemic Lupus Erythematosus, Vitiligo, Type 1 Diabetes, Alzheimer's Disease, Alopecia Areata, Crohn's, Ulcerative Colitis, Irritable Bowel Syndrome, Atherosclerosis, Dermatitis, Diverticulitis, Hepatitis, inflammatory diseases, antiinflammatory, anti-arthritic, anti-osteoporosis, anti-apoptotic, antistress, wound healing, anti-cancer, anti-aging, activities.

\section{Acknowledgement}

The authors are grateful to Dabur Research Foundation, Trivedi Science, Trivedi Global, Inc., and Trivedi Master Wellness for their support throughout the work.

\section{References}

1. Wolf A, Bauer B, Abner EL, Ashkenazy Frolinger T, Hartz AMS (2016) A comprehensive behavioral test battery to assess learning and memory in 129S6/Tg2576 mice. PLoS ONE 11(1): 0147733.

2. Van der Staay FJ, Rutten K, Erb C, Blokland A (2011) Effects of the cognition impairer MK-801 on learning and memory in mice and rats. Behab Brain Res 220(1): 215-229.

3. Reddy MS (2010) Depression: The disorder and the burden. Indian J Psychol Med 32(1): 1-2.

4. Arndt DL, Peterson CJ, Cain ME (2015) Differential rearing alters forced swim test behavior, fluoxetine efficacy, and post-test weight gain in male rats. PLoS ONE 10(7): 0131709. 
5. Kobayashi T, Hayashi E, Shimamura M, Kinoshita M, Murphy NP (2008) Neurochemical responses to antidepressants in the prefrontal cortex of mice and their efficacy in preclinical models of anxiety-like and depression-like behavior: A comparative and correlational study. Psychopharmacology (Berl) 197(4): 567-580.

6. Park DC, Schwarz N, (Eds) (2000) Cognitive Aging: A Primer. Philadelphia, Pa: Psychology Press.

7. Hasher L, Zacks RT (1988) Working memory, comprehension, and aging: A review and a new view. In: Bower GH (Edt.), The Psychology of Learning and Motivation. San Diego, Academic Press, pp.193-225.

8. Yount G, Patil S, Dave U, Alves-dos-Santos L, Gon K, et al. (2013) Evaluation of biofield treatment dose and distance in a model of cancer cell death. J Alternat Complement Med 19(2):124-127.

9. Stenger VJ (1999) Bioenergetic fields. Sci Rev Alternative Med 3.

10. Koithan M (2009) Introducing complementary and alternative therapies. J Nurse Pract 5(1):18-20.

11. Trivedi MK, Patil S, Shettigar H, Mondal SC, Jana S (2015) The potential impact of biofield treatment on human brain tumor cells: A time-lapse video microscopy. J Integr Oncol 4(3):141.

12. Trivedi MK, Patil S, Shettigar H, Gangwar M, Jana S (2015) In vitro evaluation of biofield treatment on cancer biomarkers involved in endometrial and prostate cancer cell lines. J Cancer Sci Ther 7(7):253257.

13. Trivedi MK, Branton A, Trivedi D, Nayak G, Mondal SC, et al. (2015) Antibiogram, biochemical reactions and biotyping of biofield treated Providencia rettgeri. American Journal of Health Research 3(6): 344-351.

14. Trivedi MK, Branton A, Trivedi D, Nayak G, Mondal SC, et al. (2015) Antimicrobial sensitivity, biochemical characteristics and biotyping of Staphylococcus saprophyticus: An impact of biofield energy treatment. Women's Health Care 4(6):250-271.

15. Trivedi MK, Branton A, Trivedi D, Nayak G, Shettigar H, et al. (2015) Antimicrobial susceptibility pattern, biochemical characteristics and biotyping of Salmonella paratyphi A: An impact of biofield treatment. Clin Microbiol 4:215

16. Trivedi MK, Branton A, Trivedi D, Nayak G, Mondal SC, et al. (2015) Antibiogram of biofield-treated Shigella boydii: Global burden of infections. Science Journal of Clinical Medicine 4(6):121-126.

17. Trivedi MK, Branton A, Trivedi D, Nayak G, Mondal SC, et al. (2015) Evaluation of antibiogram, genotype and phylogenetic analysis of biofield treated Nocardia otitidis. Biol Syst Open Access 4:143.

18. Trivedi MK, Branton A, Trivedi D, Nayak G, Charan S, et al. (2015) Phenotyping and 16S rDNA analysis after biofield treatment on Citrobacter braakii: A urinary pathogen. J Clin Med Genom 3:129.

19. Trivedi MK, Patil S, Shettigar H, Bairwa K, Jana S (2015) Spectroscopic characterization of chloramphenicol and tetracycline: An impact of biofield. Pharm Anal Acta 6:390-395.

20. Trivedi MK, Patil S, Shettigar H, Bairwa K, Jana S (2015) Spectroscopic characterization of biofield treated metronidazole and tinidazole. Med Chem 5:340-344.

21. Trivedi MK, Patil S, Shettigar H, Bairwa K, Jana S (2015) Effect of biofield treatment on spectral properties of paracetamol and piroxicam. Chem Sci J 6(3):90-98.

22. Trivedi MK, Branton A, Trivedi D, Shettigar H, Bairwa K, et al. (2015) Fourier transform infrared and ultraviolet-visible spectroscopic characterization of biofield treated salicylic acid and sparfloxacin. Nat Prod Chem Res 3(5):186.

23. Trivedi MK, Branton A, Trivedi D, Nayak G, Mondal SC, et al. (2015) Morphological characterization, quality, yield and DNA fingerprinting of biofield energy treated alphonso mango (Mangifera indica L.). Journal of Food and Nutrition Sciences 3:245-250.
24. Trivedi MK, Branton A, Trivedi D, Nayak G, Gangwar M, et al. (2015) Agronomic characteristics, growth analysis, and yield response of biofield treated mustard, cowpea, horse gram, and groundnuts. International Journal of Genetics and Genomics 3:74-80.

25. Trivedi MK, Branton A, Trivedi D, Nayak G, Gangwar M, et al. (2015) Analysis of genetic diversity using simple sequence repeat (SSR) markers and growth regulator response in biofield treated cotton (Gossypium hirsutum L.). American Journal of Agriculture and Forestry 3:216-221.

26. Trivedi MK, Branton A, Trivedi D, Nayak G, Gangwar M, et al. (2016) Evaluation of vegetative growth parameters in biofield treated bottle gourd (Lagenaria siceraria) and okra (Abelmoschus esculentus). International Journal of Nutrition and Food Sciences 4:688-694.

27. Trivedi MK, Tallapragada RM, Branton A, Trivedi D, Nayak G, et al. (2015) Evaluation of atomic, physical, and thermal properties of bismuth oxide powder: An impact of biofield energy treatment. American Journal of Nano Research and Applications 3:94-98.

28. Trivedi MK, Patil S, Nayak G, Jana S, Latiyal O (2015) Influence of biofield treatment on physical, structural and spectral properties of boron nitride. J Material Sci Eng 4(4): 180-181.

29. Trivedi MK, Nayak G, Patil S, Tallapragada RM, Latiyal O, et al. (2015) Characterization of physical and structural properties of brass powder after biofield treatment. J Powder Metall Min 4: 134

30. Trivedi MK, Nayak G, Patil S, Tallapragada RM, Latiyal O, et al. (2015) Evaluation of biofield treatment on physical and structural properties of bronze powder. Adv Automob Eng 4(1): 119.

31. Trivedi MK, Nayak G, Patil S, Tallapragada RM, Jana S, et al. (2015) Biofield treatment: An effective strategy to improve the quality of beef extract and meat infusion powder. J Nutr Food Sci 5(5): 300-389.

32. Trivedi MK, Tallapragada RM, Branton A, Trivedi D, Nayak G, Mishra RK, Jana S (2015) Biofield treatment: A potential strategy for modification of physical and thermal properties of gluten hydrolysate and ipomoea macroelements. Journal of Nutrtion Food Sciences 5(5): 400-414.

33. Porsolt RD, Le Pichon M, Jalfre M (1977) Depression: A new animal model sensitive to antidepressant treatments. Nature 266(5604): 730732.

34. Duman CH, Schlesinger L, Kodama M, Russell DS, Duman RS (2007) A role for MAP kinase signaling in behavioral models of depression and antidepressant treatment. Biol Psychiatry 61(5): 661-670.

35. Bromley Brits K, Deng Y, Song W (2011) Morris water maze test for learning and memory deficits in Alzheimer's disease model mice. J Vis Exp 53: 2920

36. Tanila H (2017) Testing cognitive functions in rodent disease models: Present pitfalls and future perspectives. Behav Brain Res 352: 23-27.

37. Hughes RN (2004) The value of spontaneous alternation behavior (SAB) as a test of retention in pharmacological investigations of memory. Neurosci Biobehav Rev 28(5): 497: 505.

38. Hiramatsu M, Takiguchi O, Nishiyama A (2010) Cilostazol prevents amyloid b peptide (25-35)-induced memory impairment and oxidative stress in mice. Br J Pharmacol 161(8): 1899-1912.

39. Swonger AK, Rech RH (1972) Serotonergic and cholinergic involvement in habituation of activity and spontaneous alternation of rats in a Y-maze. J Comp Physiol Psychol 81(3): 509-522.

40. Slattery DA, Cryan JF (2012) Using the rat forced swim test to assess antidepressant-like activity in rodents. Nat Protoc 7(6): 1009-1014.

41. Petit Demouliere B, Chenu F, Bourin M (2005) Forced swimming test in mice: A review of antidepressant activity. Psychopharmacol (Berl) 177(3): 245-255

42. Can A, Dao DT, Arad M, Terrillion CE, Piantadosi SC, Gould TD (2012) The mouse forced swim test. J Vis Exp 59: e3638. 
43. Morris RGM (1981) Spatial localization does not require the presence of local cues. Learning and Motivation 12(2): 239-260.

44. Han RW, Zhang RS, Chang M, Peng YL, Wang P, et al. (2012) Reversal of scopolamine-induced spatial and recognition memory deficits in mice by novel multifunctional dimers bis-cognitins. Brain Res 1470: 59-68.

45. D Hooge R, De Deyn PP (2001) Applications of the Morris water maze in the study of learning and memory. Brain Res Brain Res Rev 36(1): 60-90.

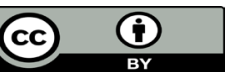

This work is licensed under Creative Commons Attribution 4.0 License

To Submit Your Article Click Here:

Submit Article

DOI: $10.32474 /$ SJPBS.2020.04.000193
46. Maurer R, Derivaz V (2000) Rats in a transparent morris water maze use elemental and configural geometry of landmarks as well as distance to the pool wall. Spatial Cognition and Computation 2: 135-156.

47. Ivens IA, Schmuck G, Machemer L (1998) Learning and memory of rats after long-term administration of low doses of parathion. Toxicol Sci 46 : $101-111$.

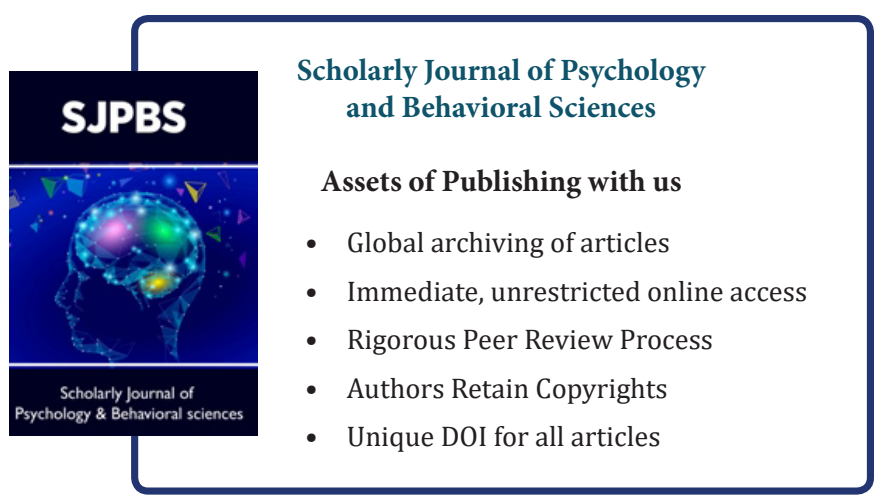

